\title{
Interaction effect of Exogenous and Endogenous variables on childhood mortality in Southern Nigeria
}

\author{
Fayehun Olufunke \\ Department of Sociology \\ University of Ibadan, Ibadan
}

DOI: 10.36108/NJSA/0102/80(0170)

Vol. 8 Issue 1, 2010

\begin{abstract}
While maternal and child health statistics in Nigeria are still relatively high, indicators from several studies show that the southern region has significantly improved over the northern region. However, the childhood mortality rate in the southern part of the country is still higher than 70/80 per 1000 live births envisaged by Millennium Development Goal Four. The contributing factors identified in the literature can be grouped into endogenous and exogenous variables. The effects of the exogenous variables are indirect because they operate through the endogenous variables to affect child's health. This study examines the interaction effect of endogenous and exogenous variables in southern Nigeria and its contributions to childhood mortality. Using the child file from Nigerian Demographic and Health Survey 2008 data, a total weighted sample of 10,769 births for southern Nigeria were selected for this study. The findings reveal that there is interaction effect of endogenous and exogenous variables on childhood mortality in Southern Nigeria. For both urban and rural area, children under five years with positive indicators have improved chances of survival than those who have less. Interacting breastfeeding pattern, source of drinking water and toilet facility with the residential area gave a robust finding, that even when the residential risk patterns are similar, the risk of childhood mortality in the urban areas is significantly lower than rural areas.
\end{abstract}

Keywords: endogenous variables, exogenous variables, interaction, under-five mortality, southern Nigeria

\section{Introduction}

Despite several laudable intervention programmes introduced to enhance child survival in Nigeria, vital statistics on under-five children remain high, with about 27 percent of them being underweight, 186 of them dying out of 1000, and just 6 percent sleeping under mosquito nets (Policy Project 2002, UNICEF 2009, WHO 2010). These facts as well as other factors have made Nigeria to be among the countries still lagging behind in achieving Millennium Development Goal Four: reducing under-five mortality to $70 / 80$ per 1000 . Studies have shown that the factors affecting under-five deaths in Nigeria, such as demographic, socioeconomics and household environment factors closely follow the analytical framework of Mosley and Chen's proximate determinants of childhood mortality in developing countries (Orubuloye and Caldwell, 1975; Caldwell, 1979; Meegama, 1980; Mosley and Chen, 1984; Adewuyi and Feyisetan, 1988). However, further research in Africa noted that there are 
distinctions between variables considered to be exogenous and endogenous in that model (Mosley and Chen, 1984; Schultz, 1984; Mutunga, 2007).

Exogenous factors are cultural, social, economic, community and regional factors, while the endogenous factors include breastfeeding patterns, hygiene, sanitary measures and nutrition. The effects of the exogenous variables are indirect because they operate through the endogenous variables. This assertion is also observed in the study by Balk et al. (2004) on the risk of infant and child death in ten West African countries. The risk of children's death is attributable to individual, household and spatially explicit geographical factors; the spatial variables explain away much of the country-specific variations in mortality which may be mediated by the household characteristics. Another study on risk, amenities and child mortality in rural South Africa by Argeseanu (2004) showed that the mother's characteristics are the most significant predictor of childhood mortality.

Place of residence also has a strong influence on child health in developing countries. Mishra and Retherford (2007) observed that rapid urban growth often outpaced the provision of safe water and sanitation, with crowded living conditions facilitating the spread of diseases that can affect child survival. This is also buttressed by Timaeus and Lush (1995) who noted that child morbidity and mortality have been strongly associated with household environmental conditions in urban areas of Ghana, Egypt, Brazil, and Thailand.

Although Nigerian maternal and child health statistics are still relatively high compared to other developing countries, indicators from several studies show that the situation in southern zones of Nigeria has significantly improved over the northern region (WHO, 2010; NPC and ICF Macro, 2009; Fayehun and Omololu, 2009). In Nigeria, the dichotomies of southern and northern region as well as rural-urban residence have been observed as a significant influence on well-being of children (NPC and ICF Macro, 2009). Iyun (2000) has identified maternal factors and household environment conditions as factors affecting childhood mortality in Southwestern Nigeria. Household environmental conditions were stronger predictors of childhood mortality in a more developed town (Ota) than the more traditional town (Iseyin). Furthermore, other studies in Nigeria have found that dirty feeding bottles and utensils, inadequate disposal of household refuse and poor storage of drinking water were significantly related to high incidence of childhood morbidity (Ayeni and Oduntan, 1980; Jinadu et al., 1991). Consequently, in seeking for ways to achieve the Millennium Development Goal Four, treated water and proper handling of sanitary facilities by mothers are essential in reducing the risk of childhood morbidity and mortality (Iyun, 2000; Rustein, 2000).

While there is ample empirical evidence that the southern part of Nigeria is at relative advantage on basic household environmental variables that affect hygiene, and with a significantly lower under-five mortality rate than the northern region, there are insufficient information on the effect of the interaction between endogenous and exogenous variables in southern Nigeria. 
Rural-urban migration in Southern Nigeria is a rapidly progressing phenomenon, which tends to increase the demands on basic infrastructure in urban areas. The research questions, therefore, include: Do the disparities in selected breastfeeding pattern, household drinking water and sanitation facility (endogenous variables) and under-five mortality as observed in the literature exist in rural-urban (exogenous variable) areas of the Southern Nigeria in the situation of increasing migratory flows? What is the influence of place of residence on the endogenous variables?

\section{Methods}

This study used quantitative secondary data from the Nigeria Demographic and Health Survey 2008 (NDHS, 2008). Nigeria is made up of six geopolitical zones, broadly grouped into the northern and southern Nigeria. The northern region comprises North Central, North East and North West, while the South West, South East and South-South zones form the southern region. Because of the focus of this study, data analysis was restricted to southern Nigeria.

Information on maternal and childhood health and mortality for SouthWest, South-East and South-South regions were extracted from the NDHS, 2008. To ensure that maternal characteristics relate to current situations, analysis was restricted to births within five years of the surveys. The sampling weights of mothers were applied for the data analysis to correct over-sampling and under-sampling. This gave a total weighted sample of 10,769 births.

The main exogenous variable considered in this study is the residence of mothers categorized into urban and rural areas. Other intervening exogenous variables are maternal highest educational attainment, age of mothers at birth, birth interval, birth order, place of work of mothers and wealth index. For this study, the endogenous variables are breastfeeding pattern, household drinking water and household sanitation facilities. The recommended duration of exclusive breastfeeding is a minimum of six months; therefore, the duration of breastfeeding (in months) is recoded into: none, below 6 months, 6-12 months, 12-24 months, and above 24 months.

Source of household drinking water is grouped into improved and unimproved. According to WHO/UNICEF Joint Monitoring Programme for Water Supply and Sanitation, improved sources of drinking water are piped water, public tap or standpipe, borehole or tube well, protected dug well/spring as well as rainwater. Unimproved sources are surface water, unprotected dug well/spring, and tanker truck/cart with small tank. Sanitation facilities are regrouped into improved and unimproved facility (WHO/UNICEF, 2004). Improved facilities are flush/pour flush to piped sewer system/septic tank/pit latrine, Ventilated Improved Pit Latrine (VIP), pit latrine with slab and composing toilet. Unimproved facilities are flush/pour flush elsewhere; pit latrine without a slab/open pit; bucket; hanging toilet. The dependent variable is whether a child is alive or dead within five years preceding the survey. 
Furthermore, a composite endogenous variable was introduced to measure the presence of good and basic indicators that can positively affect children's health. The indicators are (i) breastfed for 6 months and above (ii) improved source of drinking water and (iii) improved sanitation facility. Based on the response, this composite endogenous variable is categorized into eight values. The classifications for children under five in this analytical sample are: Group A - children who were breastfed for at least six months and live in household with improved; Group B - live in household with improved source of drinking water and improved sanitation; Group C - breastfed for at least six months and live in household with improved sanitation; Group D - breastfed for at least six months and live in household with improved source of drinking water; Group E - live in household with improved sanitation only; Group F - live in household with improved source of drinking water only; Group $\mathrm{G}$ - breastfed for at least six months only; Group $\mathrm{H}$ - do not have any of the three, that is, children who were not breastfed for at least six months and also live in household with unimproved source of drinking water and unimproved sanitation.

\section{Results}

Table 1 displays information on duration of breastfeeding, source of drinking water and sanitation facility in the household by rural-urban residence. In Southern Nigeria, at least eight out of ten children would be breastfed for a minimum of six months. While this is high, there are disparities by residence of mothers. About 50 percent of the children in rural area would still be breastfed after 12 months, while it is 44 percent in urban area. Breastfeeding for at least six months is usually recommended for infants. This is because the breast milk contains all the nutrient for children in the first few months of life and the mothers antibodies in breast milk provides immunity against diseases (NPC and ICF Macro, 2009).

As expected, there is a significant relationship between the source of drinking water and residence in Southern Nigeria. Those in rural areas are less likely to have drinking water from piped water, public tap or standpipe, borehole or tube well, protected dug well as well as rainwater. Despite the rapid urban growth and consequent urban congestion, most of the children in urban areas live in household with access to improved source of drinking water. This same pattern is observed on the household sanitation facility. The majority of the children born within the five years preceding NDHS 2008 in urban areas of Southern Nigeria live in households with good and improved sanitation facility. Conversely, 76 percent of the children under-five living in rural areas live in households with poor and unimproved sanitation facility. 
Table 1: Association between selected endogenous and exogenous variables in Southern Nigeria

\begin{tabular}{|l|c|c|c|}
\hline \multirow{2}{*}{ Endogenous variables } & \multicolumn{2}{|c|}{$\begin{array}{c}\text { Exogenous variable } \\
\text { Residence }\end{array}$} & \multirow{2}{*}{ p-value } \\
\cline { 2 - 3 } & $\begin{array}{c}\text { Rural } \\
(n=6078)\end{array}$ & $\begin{array}{c}\text { Urban } \\
(n=4692)\end{array}$ & \\
\hline Duration of Breastfeeding & $3.6 \%$ & $3.3 \%$ & \\
Never breastfed & $14.0 \%$ & $14.8 \%$ & \multirow{2}{*}{0.000} \\
Below 6 months & $31.6 \%$ & $37.6 \%$ & \\
6-12 months & $50.8 \%$ & $44.3 \%$ & \\
Above 12 months & & & \\
Source of Household drinking water & $46.2 \%$ & $14.7 \%$ & \multirow{2}{*}{0.000} \\
Unimproved source & $53.8 \%$ & $85.3 \%$ & \\
Improved source & & & \multirow{2}{*}{0.000} \\
\hline Sanitation facility & $61.5 \%$ & $23.4 \%$ & \\
Unimproved Sanitation & $38.5 \%$ & $76.6 \%$ & \\
Improved Sanitation & & & \\
\hline
\end{tabular}

The description of the composite endogenous variables introduced to measure the presence of good and basic indicators that can positively affect children's health is shown in Table 2. The basic and positive indicators are (i) breastfed for 6 months and above (ii) improved source of drinking water and (iii) improved sanitation facility.

Table 2: Description of endogenous variables by residence

\begin{tabular}{|l|c|c|}
\hline \multirow{2}{*}{ Description of endogenous variables } & \multicolumn{2}{|c|}{ Residence } \\
\cline { 2 - 3 } & $\begin{array}{c}\text { Rural } \\
(n=6078)\end{array}$ & $\begin{array}{c}\text { Urban } \\
(n=4692)\end{array}$ \\
\hline $\begin{array}{l}\text { Group A: Breastfeeding for 6mths+ \& } \\
\text { Improved source of drinking water \& } \\
\text { Improved sanitation facility }\end{array}$ & $23.3 \%$ & $55.8 \%$ \\
\hline $\begin{array}{l}\text { Group B: Improved source of drinking water \& } \\
\text { Improved sanitation facility }\end{array}$ & $4.6 \%$ & $11.6 \%$ \\
\hline $\begin{array}{l}\text { Group C: Breastfeeding for 6mths+ \& } \\
\text { Improved sanitation facility }\end{array}$ & $8.8 \%$ & $7.3 \%$ \\
\hline $\begin{array}{l}\text { Group D: Breastfeeding for 6mths+ \& } \\
\text { Improved source of drinking water }\end{array}$ & $21.3 \%$ & $14.8 \%$ \\
\hline Group E: Improved sanitation facility alone & $1.8 \%$ & $1.8 \%$ \\
\hline Group F: Improved source of drinking water alone & $4.5 \%$ & $3.1 \%$ \\
\hline Group G: Breastfeeding for 6mths+ alone & $29.5 \%$ & $4.8 \%$ \\
\hline Group H: ${ }^{a}$ NONE & $6.1 \%$ & $0.9 \%$ \\
\hline
\end{tabular}

a None - unimproved source of drinking water \& unimproved sanitation facility \& breastfeeding $<6$ months 
A comparison of the composite endogenous variable for rural and urban areas reveals a significant difference $(\mathrm{p}<0.05)$. Less than one percent of children in urban areas in Southern Nigeria are never breastfed, live in household with unimproved source of drinking water and sanitation facility, whereas, six percent of the children in rural areas are in the same situation. More urban children are well breastfed, live in households with improved source of drinking water and sanitation facility than children rural areas.

The result for the group of children under-five who were never breastfed or breastfed for less than 6months, but have improved sanitation and drinking water (Group B) is as expected from the literature. These children are fewer in rural areas than urban areas of the Southern part of Nigeria. However, children who live in households with no access to improved drinking water and sanitation but are breastfed for a minimum of 6 months; Group $\mathrm{G}$ are more in the rural areas. Despite the obvious disadvantage in this group, who are likely to be of low socioeconomic status in the two residential areas, the practice of infant breastfeeding for the recommended minimum of 6 months seems to be well-observed in rural areas (29.5\%) than urban areas (4.8\%). It can be inferred from this study that mothers in rural areas, who have little or no access to basic facilities that can improve hygiene are more likely to fully breastfeed their babies for a minimum period of 6 months than their urban counterparts, which confers some health advantage on their children.

Further analysis on the odds of childhood mortality for different groups is in Table 3; urban area is the reference category for each of the group. The survival chances of a child in urban area if he/she is well breastfed and lives in household with improved drinking water and sanitation facility (Group A) did not significantly differ from those in the rural area; likewise, those in Groups $\mathrm{C}, \mathrm{D}, \mathrm{E}, \mathrm{G}$ and $\mathrm{H}$. However, if there are both improved drinking water and sanitation (Group B), but the child is not adequately breastfed, the risk of under-five mortality in rural area is significantly higher than the urban area. Likewise, if the only positive variable in the household is improved drinking water (Group F), a child living in such household in urban areas is likely to have significant reduced risk of death compared to rural areas.

It is observed that irrespective of the provision of adequate basic facilities such as improved drinking water and sanitation in the household, a salient conclusion from this study is that breastfeeding for at least six months is very crucial to child survival and can bridge the urban-rural gap in under-five mortality in Southern Nigeria. A child that is adequately breastfeed for at least six months and lives in rural areas of Southern Nigeria is more likely to have the same risk of death as their counterparts in the urban areas. 
Table 3: Odds of childhood mortality by different groups

\begin{tabular}{|c|c|c|c|}
\hline GROUPS & $\begin{array}{c}\text { Endogenous and Exogenous } \\
\text { variables }\end{array}$ & Odds ratio & Significance \\
\hline $\mathbf{A}$ & $\begin{array}{l}\text { ALL: Breastfeeding \& drinking } \\
\text { water \& Sanitation facility } \\
\text { Rural } \\
\text { Urban (ref) }\end{array}$ & $\begin{array}{l}1.181 \\
1.000\end{array}$ & $\begin{array}{l}\text { No significant } \\
\text { difference between } \\
\text { urban and rural area }\end{array}$ \\
\hline B & $\begin{array}{l}\text { Drinking water \& Improved } \\
\text { sanitation facility only } \\
\text { Rural } \\
\text { Urban (ref) }\end{array}$ & $\begin{array}{l}1.758^{*} \\
1.000\end{array}$ & $\begin{array}{l}\text { Rural under-five } \\
\text { deaths is significantly } \\
\text { higher than urban }\end{array}$ \\
\hline $\mathrm{C}$ & $\begin{array}{l}\text { Breastfeeding \& Improved } \\
\text { sanitation facility only } \\
\text { Rural } \\
\text { Urban (ref) }\end{array}$ & $\begin{array}{l}0.952 \\
1.000\end{array}$ & $\begin{array}{l}\text { No significant } \\
\text { difference between } \\
\text { urban and rural area }\end{array}$ \\
\hline D & $\begin{array}{l}\text { Breastfeeding for 6mths+ \& } \\
\text { Improved source of drinking water } \\
\text { only } \\
\quad \text { Rural } \\
\quad \text { Urban (ref) }\end{array}$ & $\begin{array}{l}1.475 \\
1.000\end{array}$ & $\begin{array}{l}\text { No significant } \\
\text { difference between } \\
\text { urban and rural area }\end{array}$ \\
\hline $\mathbf{E}$ & $\begin{array}{l}\text { Improved sanitation facility alone } \\
\text { Rural } \\
\text { Urban (ref) }\end{array}$ & $\begin{array}{l}1.637 \\
1.000\end{array}$ & $\begin{array}{l}\text { No significant } \\
\text { difference between } \\
\text { urban and rural area }\end{array}$ \\
\hline $\mathbf{F}$ & $\begin{array}{l}\text { Improved source of drinking water } \\
\text { alone } \\
\text { Rural } \\
\text { Urban (ref) }\end{array}$ & $\begin{array}{c}2.376^{*} \\
1.000\end{array}$ & $\begin{array}{l}\text { Rural under-five } \\
\text { deaths is significantly } \\
\text { higher than urban }\end{array}$ \\
\hline $\mathbf{G}$ & $\begin{array}{l}\text { Breastfeeding for } 6 \text { mths+ alone } \\
\text { Rural } \\
\text { Urban (ref) }\end{array}$ & $\begin{array}{l}0.926 \\
1.000\end{array}$ & $\begin{array}{l}\text { No significance } \\
\text { difference between } \\
\text { urban and rural area }\end{array}$ \\
\hline $\mathbf{H}$ & $\begin{array}{l}{ }^{\text {a NONE: }} \\
\text { Rural } \\
\text { Urban }\end{array}$ & $\begin{array}{l}2.233 \\
1.000\end{array}$ & $\begin{array}{l}\text { No significance } \\
\text { difference between } \\
\text { urban and rural area }\end{array}$ \\
\hline
\end{tabular}

${ }^{a}$ None - unimproved source of drinking water \& unimproved sanitation facility \& breastfeeding $<6$ months

$*$ p-value $<0.05$

The interaction effect of the selected endogenous and exogenous variables on childhood mortality in Southern Nigeria is further explored by examining the within residence effect. Using children under the age of five years, who were breastfed for at least six months and live in household with improved source of drinking water and sanitation as the reference category for each of the residential area, the result in Table 4 shows slight disparity for the two locations.

In rural areas of Southern Nigeria, the risk of death for under-five children that live in household with just improved source of drinking water is significantly higher than any other group. It is surprising that this group's risk of under-five death is higher than even those who did not have any positive indicator. It is further noted that those at higher risk of childhood mortality in 
rural areas are children who were not breastfed for at least six months. While there is a significant difference between those who have all the positive indicators and those who were just breastfed alone, the difference is not as wide as the groups, who were not given breast milk at all.

Table 4: Interaction Effect of Endogenous and Exogenous variables on childhood mortality

\begin{tabular}{|lcc|}
\hline Interacting Terms & Rural & Urban \\
\hline Breastfeeding *Water*Sanitation (ref.) & $\mathbf{1 . 0 0 0}$ & $\mathbf{1 . 0 0 0}$ \\
Water* Sanitation & $8.348^{*}$ & $5.607^{*}$ \\
Breastfeeding*Sanitation & 1.347 & $1.670^{*}$ \\
Breastfeeding *Water & 1.214 & 0.972 \\
Sanitation & $7.223^{*}$ & $5.210^{*}$ \\
Water & $10.607^{*}$ & $5.273^{*}$ \\
Breastfeeding & $1.582^{*}$ & $2.017^{*}$ \\
${ }^{a}$ None & $9.003^{*}$ & $4.762^{*}$ \\
\hline a None - unimproved source of drinking water \& unimproved sanitation facility \& \\
breastfeeding < 6 months \\
* p-value <0.05
\end{tabular}

There is a slight similarity in the odds of childhood mortality in rural and urban area of the southern part of Nigeria. The risk of under-five death is significantly higher for those who were not breastfed for at least six months in the urban area. However, differences are observed among those children, who were breastfed and live in household with improved sanitation when compared with the reference category in urban area. There is a significant higher risk in urban areas (1.67) than in rural areas (1.35). The result from this study reveals that breastfeeding is a significant endogenous variable that can interact with residence to predict the death of under-five children in both rural and urban areas of Southern Nigeria.

\section{Conclusion}

The interaction effect of endogenous and exogenous variables on childhood mortality is demonstrated in this study. The study empirically showed the differences between the 'haves' and the 'have-nots' living in the same residential area. For both urban and rural areas, children under-five with positive indicators have improved chances of survival than those who have less. Interacting breastfeeding pattern, source of drinking water and toilet facility with the residential area gave a robust finding that though the residential risk pattern may be similar, the risk of childhood mortality in urban areas is significantly lower than rural areas.

The findings also support previous conclusions in the literature on the usefulness of the Mosley and Chen analytical framework for the study of child survival in less developed countries. While several studies in Nigeria and other 
Sub-Saharan Africa countries on childhood mortality have found that unimproved source of drinking water and unimproved toilet facilities affect childhood mortality, there is the need to emphasize breastfeeding especially for a minimum period of six months (Ayeni and Oduntan, 1980; Jinadu et al.,

1991, Rustein, 2000). As emphasized in this study, as much as source of drinking water and toilet facility need to be improved, a child who is breastfed for six months will survive to age five more than one living in a household with basic infrastructure in both rural and urban areas of Southern Nigeria. A policy thrust, therefore, is to encourage breastfeeding as well as improving household drinking water and sanitation throughout Nigeria.

\section{References}

Adewuyi, A.A. \& Feyisetan B.J. 1988. Correlates of Infant Mortality: Empirical evidence from Ile-Ife, Nigeria. Manuscript Report 191e IDRC, Canada.

Argeseanu, S. 2004. Risks, amenities and child mortality in rural South Africa. African Population Studies, 19:1.

Ayeni, O. \& Oduntan, S.O. 1980. Infant mortality rates and trends in Nigerian rural population. Journal of Tropical Pediatrics and Environmental Child Health, 26(1): 7-10.

Balk, D.; Pullum, T.; Storeygard, A.; Greenwell, F. \& Neuman, M. 2004. A spatial analysis of childhood mortality in West Africa. Population, Space and Place 10:175-216.

Caldwell, J.C. 1979. Education as a factor in mortality decline: An examination of Nigerian data. Population Studies, 33(3):395-414.

Fayehun O.A and Omololu O.O. 2009. Prevalence and Treatment of childhood diarrhea among Nigerian ethnic groups. The Nigerian Journal of Sociology and Anthropology. Vol. 7(2): 14-28.

Iyun, B.F. 2000. Environmental factors, situation of women and child mortality in south western Nigeria. Social Science and Medicine, 51(10):1473 -1489.

Jinadu, M.K.; Olusi, S.O.; Agun, J.I. \& Fabiyi A.K. 1991. Childhood diarrhea in rural Nigeria: Studies on prevalence, mortality and socio-environmental factors. Journal of Diarrhea Diseases Research 9(4): 323-327.

Meegama, S.A. 1980. Socio-economic determinants of infant and child mortality in Sri Lanka: An analysis of post war experience, 151 World Fertility Survey Scientific Reports No.8.

Mishra, V. \& Retherford, R.D. 2007. Does biofuel smoke contribute to anaemia and stunting in early childhood? International Journal of Epidemiology Vol.36 pp117-129.

Mosley, W.H. \& Chen, L.C. 1984. An analytical framework for the study of child survival in developing countries. Child Survival: Strategies for Research, Supplement to Population and Development Review 10:25-45. 
Mutunga, J.C. 2007. Environmental determinants of child mortality in urban Kenya. United Nation-World Institute for Development Economic Research (UNU_WIDER) Paper 83 Retrieved online on January 2007. http://www.wider.unu.edu/publications/working-papers/researchpapers/2007/en_GB/rp2007-83/_files/78708549946179884/default/rp200783.pdf.

National Population Commission (NPC) (Nigeria) and ICF Macro. 2009. Nigeria Demographic and Health Survey, 2008, Abuja, Nigeria: National Population Commission and ICF Macro.

Orubuloye, I.O. \& Caldwell, J.C. 1975. The impact of public health services on mortality: A study of mortality differentials in a rural area of Nigeria. Population Studies, 29: 259-272.

Policy Project/Nigeria. 2002. Child survival in Nigeria: Situation response and prospect: Key Issue. Abuja Policy Project.

Rutstein, S.O. 2000. Factors associated with trends in infant and child mortality in developing countries during the 1990s. Bulletin of the World Health Organisation 78:1256-1270.

Schultz, T.P. 1984. Studying the impact of household, economic and community variables on child mortality, Population and Development Review, 10 supplementary: 215-235.

Timaeus, I.M. \& Lush, L. 1995. Intra-urban differentials in child health. Health Transition Review 5:163-190.

World Health Organisation. 2010. World Health Statistics 2010. Geneva: The World Health Organisation 